\title{
Violence and Public Health
}

How can the health sector respond to violence?

\section{GUEST EDITORS}

\author{
Alison Rutherford ${ }^{\mathrm{A}, \mathrm{B}}$ and Anthony B. Zwi ${ }^{\mathrm{A}}$ \\ ${ }^{\mathrm{A} S}$ School of Public Health and Community Medicine, University of NSW \\ ${ }^{\mathrm{B} C o r r e s p o n d i n g ~ a u t h o r: ~ a . r u t h e r f o r d @ u n s w . e d u . a u ~}$
}

In 2007 violence is again on the front pages of our newspapers. As we write this editorial, a massacre of students at a university in the United States is igniting fresh debate about gun control there. Closer to home, the media is focusing on issues related to alcohol and violence in NSW. There is evidence that controlling alcohol consumption will have an effect on the occurrence of violence; debate is ongoing, and a policy response demanded by many public health practitioners. Bullying in schools and workplaces is also attracting increasing attention.

The health sector is at the forefront of responding to violence. Most health workers have experience of dealing with the effects of violence whether attending to victims in the small hours of the morning, notifying the Department of Community Services of a child at risk of abuse or managing aggressive clients in our services.

The health sector clearly has a role in mitigating the effects of violence, but what is its role in prevention? This is far more contentious, and many public health practitioners place violence prevention in the 'too hard' basket.

The first special issue of the Bulletin focusing on violence ${ }^{1}$ investigated patterns of violence in NSW and examined, in particular, violence associated with injecting drug use and prison settings. In this issue, we focus on the challenge of interventions to prevent violence.

In common with other public health strategies, violence prevention interventions can be primary, secondary or tertiary, and can be population based or targeted towards individuals or communities at particular risk. The NSW Families First initiative, for example, is a population-based, primary prevention strategy, and one of the reported out- comes is reducing the risk of abuse of children and of the perpetration of violence in young adulthood. ${ }^{2}$ Another example of preventive efforts is the night patrols instigated by some Indigenous communities - these are targeted towards young people and those under the influence of alcohol who are at highest risk of experiencing a violent incident. In contrast to unintentional injury prevention, preventing intentional injuries or violence often requires an enhanced focus on behavioural factors, such as relationship or conflict resolution skills. However, some more 'passive' environmental strategies have also been effective, such as designing public spaces so that people can see and interact with others. Most successful strategies are multisectoral and are tailored to the unique characteristics of particular communities.

In this issue of the Bulletin, we discuss the data sources that can be used to better understand violence in NSW. We argue that violence, according to the WHO definition, is a bigger problem in NSW than suggested by inpatient statistics. Our current data sources only partially capture the extent of violence, and our mechanisms for reviewing these data and feeding them back into policy processes are inadequate. Following through from research to enhancing policy and practice is an important and recurring theme in this Bulletin. NSW does not differ dramatically in terms of violence from other Australian states where violence remains a significant cause of harm; those most at risk are young adults, those living in rural and remote areas and Indigenous people. Men are most at risk of public violence and women of violence that occurs in private.

Is there any good news? There might be. A successful violence prevention program, the Alcohol Linking Program, has been initiated within the health sector and has now been 
adopted by NSW Police across the whole state. The Alcohol Linking Program targets a specific risk factor in a geographical place, alcohol use on licenced premises. Police provide feedback to licencees on alcohol-related incidents associated with their premises. Wiggers, in this issue, reports that data collected for the program demonstrate that a small number of premises are responsible for a large proportion of incidents. This article demonstrates how this strategy can significantly reduce the number of violent incidents associated with a particular locality.

Secondary prevention, or reducing harm and adverse outcomes in victims, is the dominant paradigm for addressing domestic violence across most sectors. An important secondary prevention initiative instigated by NSW Health is the NSW Screening Program for Domestic Violence. The Program aims to identify current victims of domestic violence attending health services and help put in place strategies to reduce long-term harm. Spangaro's paper provides a summary of how the program has been implemented in NSW, and discusses important debates around how to ensure that screening is effective, ethical and safe.

Breckenridge and Maloney report on a qualitative study investigating how women can be enabled to stay in their homes after leaving a relationship with a violent partner. The authors make explicit the links between the health impacts of domestic violence, such as post traumatic stress disorder, depression and substance abuse, and the compounding effects of insecure housing and homelessness. An intervention based on this research is now being piloted in two Area Health Services.
Given the importance of whole of sector approaches in violence prevention, Harris et al. take a critical look at the 'whole of government' approach to tackling violence, and challenge the reader to consider the notion of community on which these are based. Given the challenges of working intersectorally, and the relative lack of evidence for 'whole of government' strategies to prevent violence, the authors argue for stronger intersectoral discussions before the implementation of interventions, with a clear focus on what could concretely be expected to be achieved. Systematic development of a shared 'program logic', the authors argue, is the key to successful whole of government interventions.

The papers presented here tell us that violence can indeed be prevented. However, to be effective, interventions must be informed by evidence, and interventions invariably require implementation in a coordinated manner across sectors. While other sectors already see health practitioners as key partners with unique insights in relation to violence prevention, they tend to focus on the clinical care role of health practitioners. Within public health and health promotion we are increasingly recognising what can and should be done, much of it upstream in relation to prevention. Failing to do so will leave untouched the unacceptable levels of this daily threat to safety and security.

\section{References}

1. N S W Public Health Bull 2006; 17(1-2).

2. First F. A NSW Government Initiative. Available at http://www.familiesfirst.nsw.gov.au [Verified 18 May 2007]. 